\title{
Role of olmesartan in combination therapy in blood pressure control and vascular function
}

\author{
This article was published in the following Dove Press journal: \\ Vascular Health and Risk Management \\ 6 August 2010 \\ Number of times this article has been viewed
}

\section{Carlos M Ferrario \\ Ronald D Smith}

Wake Forest University School of Medicine, Winston-Salem,

North Carolina, USA
Correspondence: Carlos M Ferrario

Wake Forest University School

of Medicine, Winston-Salem,

NC 27I57, USA

Tel + I 336-7I 6-9266

Fax + I 336-7| 6-6644

Email cferrari@wfubmc.edu

\begin{abstract}
Angiotensin receptor blockers have emerged as a first-line therapy in the management of hypertension and hypertension-related comorbidities. Since national and international guidelines have stressed the need to control blood pressure to $<140 / 90 \mathrm{mmHg}$ in uncomplicated hypertension and $<130 / 80 \mathrm{mmHg}$ in those with associated comorbidities such as diabetes or chronic kidney disease, these goal blood pressures can only be achieved through combination therapy. Of several drugs that can be effectively combined to attain the recommended blood pressure goals, fixed-dose combinations of angiotensin receptor blockers and the calcium channel blocker amlodipine provide additive antihypertensive effects associated with a safe profile and increased adherence to therapy. In this article, we review the evidence regarding the beneficial effects of renin-angiotensin system blockade with olmesartan medoxomil and amlodipine in terms of blood pressure control and improvement of vascular function and target organ damage.
\end{abstract}

Keywords: amlodipine, angiotensin receptor blockers, angiotensin-converting enzyme 2, hypertension, renin-angiotensin system

\section{Introduction}

The 33rd report on the Health Status in the United States estimates that essential hypertension affects $17.9 \%$ of the age-adjusted, 20 -year-old or older white subjects and up to $26 \%$ of male African Americans (http://www.cdc.gov/nchs/data/hus/hus09. pdf). Numerous large-scale clinical trials have documented the benefits of strict blood pressure control in preventing hypertension-related cardiovascular events. It is clear that the benefit of blood pressure reduction to $120 / 80 \mathrm{mmHg}$ in non-diabetic patients will be associated with a large reduction in the occurrence of strokes and fatal and nonfatal ischemic heart diseases. Since single-drug therapy is often not able to lower blood pressure to these ideal values, recent recommendations now emphasize the need for combination therapy to achieve these blood pressure goals. ${ }^{1,2}$ Although no definitive evidence is available as to which combination therapy will most effectively achieve strict blood pressure control and reduction in target organ damage, the increased use of angiotensin-converting enzyme (ACE) inhibitors, angiotensin receptor blockers (ARBs), and the calcium channel blocker (CCB) amlodipine, widely prescribed alone or in combination in most countries in the world, favors their use.

Evidence-based medicine from large controlled clinical trials supports the use of these drugs, although the long-term benefit of any one combination over the others remains to be established. ${ }^{3}$ In this context, the Avoiding Cardiovascular Events through COMbination Therapy in Patients LIving with Systolic Hypertension (ACCOMPLISH) study showed that the combination of benazepril and amlodipine resulted in outcome 
benefits greater than those observed in subjects medicated with benazepril and hydrochlorothiazide (HCTZ) despite similar blood pressure reductions. ${ }^{4,5}$ Although both ACE inhibitors and ARBs have a definitive role in preventing the consequences of increased renin-angiotensin system activity in cardiac, vascular, and renal functions, enhanced tolerability and the more specific effects of ARBs on suppressing the binding of angiotensin II (Ang II) to the subtype 1 ( $\mathrm{AT}_{1}$ ) receptor should favor the use of ARBs over blockers of ACE. This article summarizes the evidence for the combined use of the $\mathrm{AT}_{1}$ selective receptor antagonist, olmesartan medoxomil, with amlodipine on blood pressure control and target organ damage. Additional information regarding the pharmacological and clinical response to olmesartan administration are reviewed elsewhere. ${ }^{6-9}$

\section{Pharmacodynamics of olmesartan and amlodipine}

Olmesartan medoxomil is a highly selective ARB with pharmacokinetic characteristics that determine high binding to $\mathrm{AT}_{1}$ receptors and lasting effects on arterial pressure. ${ }^{10,11}$ The medoxomil ester of olmesartan facilitates its bioavailability as the oral bioavailability of the active product RNA- 6270 is less than $4.5 \% .^{12}$ In bovine adrenal cells, the displacement of ${ }^{125} \mathrm{I}$-Ang II by olmesartan has an half maximal inhibitory concentration $\left(\mathrm{IC}_{50}\right)$ value of $7.7 \mathrm{nM}$, a displacement value significantly lower than that of losartan $(92 \mathrm{nM})$ and its active metabolite EXP3174 (16 nM). Figure 1 shows that the affinity of olmesartan for $\mathrm{AT}_{1}$ receptors is high when compared with that of other ARBs. Furthermore, the displacement of olmesartan by Ang II in Hill's plots shows that the active drug behaves as a competitive antagonist of $\mathrm{AT}_{1}$ receptors. ${ }^{13}$ Pharmacokinetic properties of olmesartan support its efficacy and long duration of action when given to experimental animals and humans. Additional information on pharmacokinetics of olmesartan and its mode of action are discussed elsewhere. . $^{8,9,14}$

The antihypertensive actions of olmesartan are potentiated when used in combination with either thiazide diuretics or CCBs. Amlodipine is a potent dihydropyridine CCB having a high degree of ionization, high oral bioavailability $(60 \%-$ $65 \%$ ), and peak plasma concentrations attainable within 6-8 hours after oral administration. Like other dihydropyridine $\mathrm{CCB}$, amlodipine selectively inhibits calcium $\left(\mathrm{Ca}^{2+}\right)$ influx across cell membranes in cardiac and vascular smooth muscle with a greater effect on the latter. ${ }^{15}$ Rohatagi et al ${ }^{16}$ reported the pharmacokinetics of olmesartan medoxomil and amlodipine besylate alone and in a fixed-dose combination in five phase I crossover studies in healthy volunteers. The similarity of the mean steady-state pharmacokinetics of olmesartan and amlodipine at doses of 40 and $10 \mathrm{mg}$, respectively, their drug concentration-time curves, and the maximum observed plasma drug concentrations within their prespecified bioequivalence ( $80 \%-125 \%)$ showed that they were well suited to coadministration in a fixed-dose combination. ${ }^{16}$ Furthermore, coadministration of amlodipine besylate and

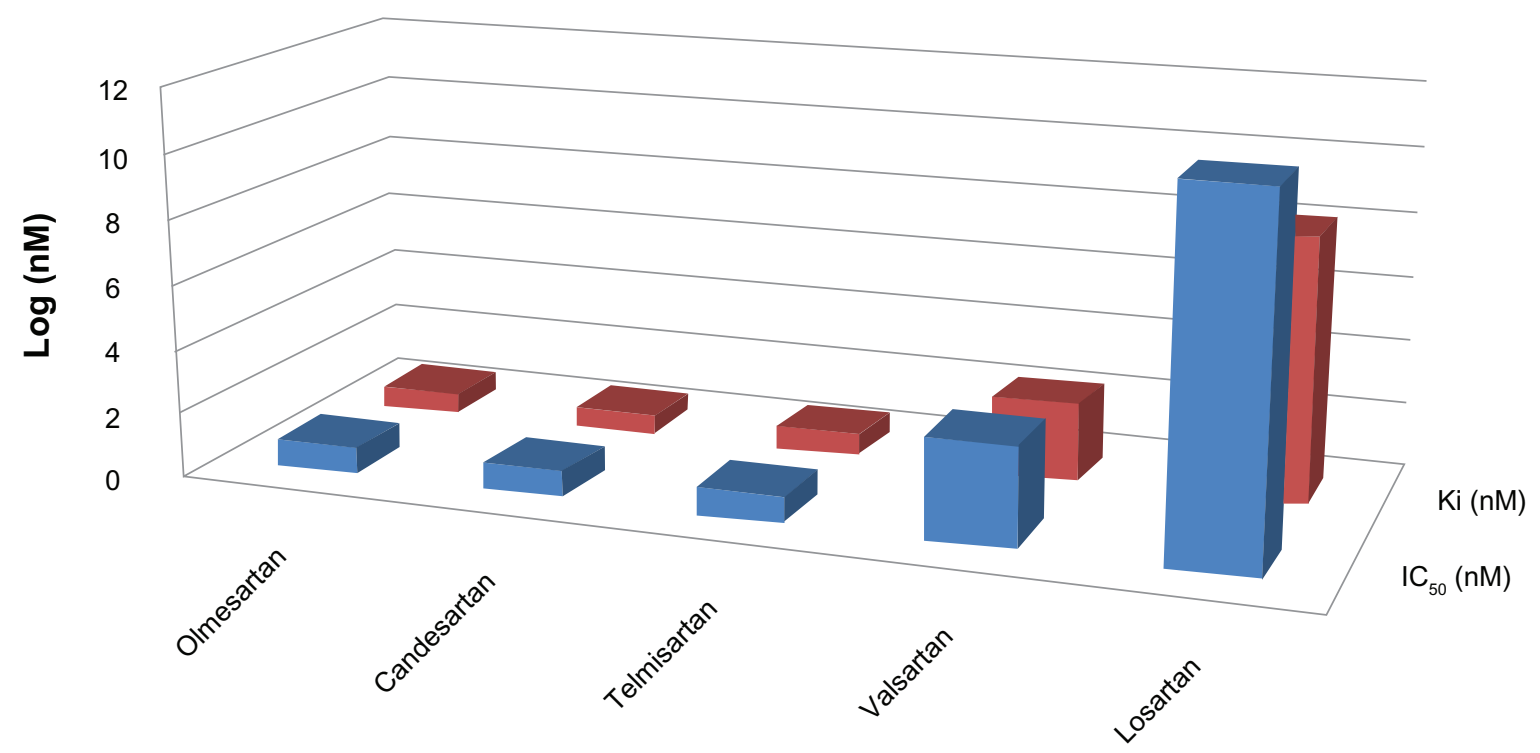

Figure I Comparative pharmacodynamic characteristics of five angiotensin receptor blockers in terms of their half maximal inhibitory concentration (IC ${ }_{50}$ ) and dissociation constant (Ki). The active form of olmesartan shows high affinity for AT, receptors with an $\mathrm{IC}_{50}$ equivalent to that of candesartan and much lower than the IC $\mathrm{C}_{50}$ for other angiotensin receptor blockers. Similarly, the lowest $I C_{50}$ for olmesartan is associated with the lowest dissociation constant from the receptor. 
olmesartan medoxomil, as commercially available separate dosage forms, for 10 days showed no evidence of any negative pharmacokinetic drug-drug interactions. ${ }^{16}$

The additive mechanisms of action of the single-dose form of olmesartan/amlodipine on long-term hemodynamic and neurohormonal systems controlling blood pressure have not been studied. Results from the direct effects of olmesartan or amlodipine on cardiac and vascular structures and hypertension-induced remodeling suggest complementary actions. Olmesartan induces a reduction in peripheral vascular resistance that is associated with no changes in heart rate or cardiac output and increases in plasma renin activity (see Schindler and Ferrario 9 for review). In the EUropean Trial on Olmesartan and Pravastatin in Inflammation and Atherosclerosis (EUTOPIA trial),${ }^{17}$ olmesartan was found to lower the serum levels of high-sensitivity C-reactive protein, tumor necrosis factor- $\alpha$ (TNF- $\alpha$ ), interleukin-6 (IL-6), and human monocyte chemoattractant protein-1 (MCP-1). A further reevaluation of the EUTOPIA trial showed that the vasculoprotective effects of olmesartan were associated with decreases in plasma osteopontin concentrations. ${ }^{18}$ The anti-inflammatory effects of $\mathrm{AT}_{1}$ receptor blockade with olmesartan may contribute to the observation that this drug can prevent the progression of atherosclerosis in nonhuman primates. ${ }^{19}$ Additional vasculotropic effects of olmesartan in the protection of vascular endothelial function have been reviewed recently. ${ }^{8}$ Although the long-term effect of olmesartan on the plasma and tissue concentrations of Ang II requires further study, a report by Ichikawa et $\mathrm{al}^{20}$ showed that blockade of $\mathrm{AT}_{1}$ receptors may not be associated with the typical increase in plasma Ang II concentrations, as observed with other ARBs. ${ }^{21}$ This clinical study may be tentatively explained by the observation that $\mathrm{AT}_{1}$ blockade upregulates the activity and tissue expression of ACE 2, a homolog of ACE that acts as a monocarboxypeptidase degrading Ang II into the vasodilator and antitrophic peptide angiotensin-(1-7) [Ang-(1-7)].22-27 In keeping with these findings, an experimental study in the stroke-prone rat suggested that olmesartan may act as an inhibitor of ACE through the stimulation of Ang-(1-7) actions and release of nitric oxide. ${ }^{28}$

The beneficial effects of olmesartan on the prevention of vascular remodeling and carotid artery atherosclerotic plaque progression in subjects with hypertension are now documented. ${ }^{29,30}$ The Multicentre Olmesartan atherosclerosis Regression Evaluation (MORE) study was a double-blind trial conducted in patients with hypertension who are at increased cardiovascular risk (presence of carotid wall thickening and a defined atherosclerotic plaque), using noninvasive two- and three-dimensional ultrasonography. The trial compared the effects of a 48-month treatment based on either olmesartan medoxomil or atenolol on common carotid intima-media thickness and plaque volume (PV). ${ }^{30}$ Large PVs $(>33 \mu \mathrm{L})$ were significantly reduced over the 102week treatment period only in those subjects assigned to the olmesartan-based therapy. In agreement with these findings, administration of olmesartan to subjects with diabetes was associated with reduced arterial stiffness while amlodipine had no effect. ${ }^{31}$

The Vascular Improvement with Olmesartan Study (VIOS) enrolled 100 subjects with stage 1 hypertension without diabetes, to evaluate whether an olmesartan-based therapeutic regimen could reverse vascular hypertrophy independent of the magnitude of blood pressure lowering. ${ }^{29,32}$ The trial compared the effects of olmesartan-based therapy versus atenolol-based therapy on blood pressure control and changes in wall/media lumen $(\mathrm{W} / \mathrm{L})$ ratio from small resistance arterioles obtained from these patients through the technique of gluteal biopsies. ${ }^{32-34}$ Biopsies were available from 22 atenolol recipients (100 mg/day), 27 olmesartan medoxomil recipients (40 mg/ day), and 11 normal volunteer controls. Additional antihypertensive medications (HCTZ 12.5-25 mg/day, amlodipine 5-10 mg/day, or hydralazine 50-100 mg twice daily) were dispensed to achieve blood pressure control below 140/90 $\mathrm{mmHg}$. Overall, patients in the atenolol-based regimen group required more medications versus patients randomized to the olmesartan-based group. Furthermore, a greater percentage of patients assigned to the olmesartan-based therapy achieved and maintained an ideal blood pressure of $\leq 120 / 80 \mathrm{mmHg}$ at 4 weeks $(24 \%$ in the olmesartan-based therapy vs $8 \%$ in those assigned to the atenolol-based therapy $[P<0.05])$. At the completion of the 52-week period, comparable decreases in arterial pressure resulting in the physiological levels of blood pressure $(\leq 120 / 80 \mathrm{mmHg})$ were observed in patients assigned to each of the two regimens. Normalization of blood pressure, however, was associated with the regression of vascular hypertrophy only in those subjects assigned to the olmesartan-based therapy (Figure 2). In these subjects, the reduction in $\mathrm{W} / \mathrm{L}$ ratio of small resistance vessels (from $14.9 \%$ to $11.1 \% ; P<0.01$ ) was numerically equivalent to the $\mathrm{W} / \mathrm{L}$ ratio determined in the subset of normotensive volunteers from whom subcutaneous small arteriole resistance vessels were obtained. ${ }^{32}$ Since the addition of HCTZ and amlodipine were required in more than $59 \%$ of the subjects and no differences existed in the dosing and time periods in which these agents were incorporated to the treatment regimen 


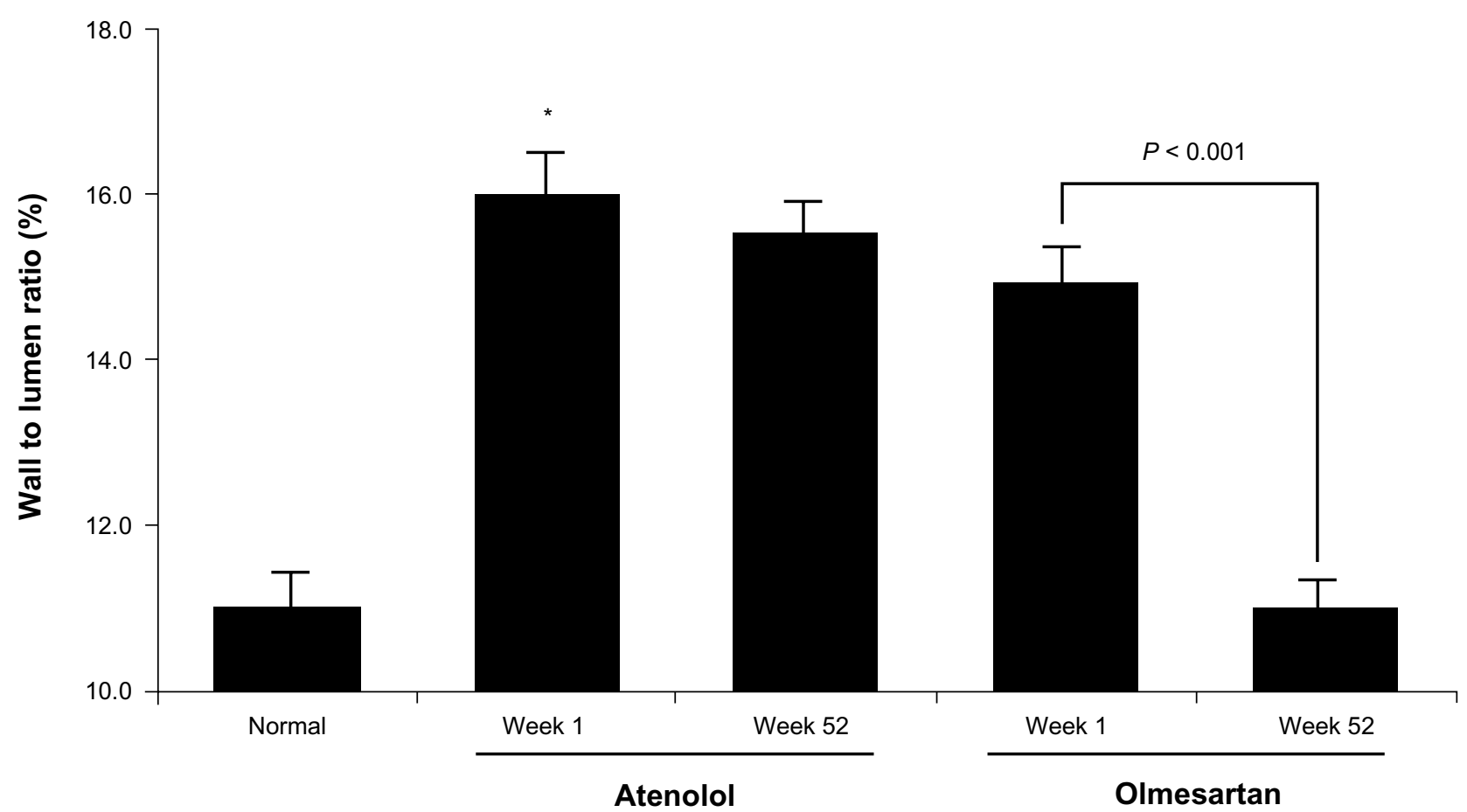

Figure 2 Bar graph denotes the average value of wall/media lumen ratio from small resistance arterioles obtained from normotensive subjects (normal) and patients with hypertension without diabetes assigned to either an atenolol-based or olmesartan-based therapy before and at week 52 after completion of the treatment regimen. Note: Values are means \pm standard error of the mean. ${ }^{*} P<0.005$ compared with normal. Drawn from data of Smith et al. ${ }^{32}$

for both arms of the study, the data demonstrated that the selective effect of $\mathrm{AT}_{1}$ receptor blockade in the reversal of vascular hypertrophy in small resistance vessels was directly responsible for the reduction of peripheral vascular resistance. ${ }^{32,33}$ Furthermore, noninvasive measurements of central aortic pressure and determination of the augmentation index by applanation tonometry ${ }^{35}$ showed decreases in the indices of vascular compliance only on those subjects receiving the olmesartan-based therapy. ${ }^{32}$ On the other hand, a study that investigated the role of cellular oxidant stress and inflammation on patients with hypertension and the cardiometabolic syndrome showed comparative effects induced by treatment with either olmesartan or amlodipine. ${ }^{36} \mathrm{~A}$ small sample size and the presence of comorbidities may have contributed to the reported conclusions. ${ }^{36}$

\section{Clinical studies}

A series of studies have documented the effective control of arterial pressure achieved with the daily fixed-dose administration of a single tablet of olmesartan/amlodipine. A multicenter, double-blind, randomized, placebo-controlled, parallel-group, factorial study, lasting 8 weeks and enrolling 1,940 subjects with stage 1 and stage 2 hypertension, evaluated the blood pressure response to placebo, amlodipine (5-10 mg/day), olmesartan (10, 20, and $40 \mathrm{mg} /$ day), and the fixed combination of olmesartan and amlodipine at doses of 5/10,5/20, 5/40, 10/10, 10/20, and 10/40 mg/day. ${ }^{37}$ At the highest dose combination of olmesartan/amlodipine ( $40 / 10 \mathrm{mg} /$ day), the reduction in systolic and diastolic blood pressures amounted to 28.5 and $19.4 \mathrm{mmHg}$, respectively. ${ }^{37}$ The decreases in arterial pressure were significantly greater than those obtained with either olmesartan or amlodipine when given alone. ${ }^{37}$ The beneficial effects of the single-tablet combination were associated with increased target blood pressure of $<140 / 90 \mathrm{mmHg} .{ }^{37}$ Although all treatment regimens in the Combination of Olmesartan medoxomil and Amlodipine besylate in Controlling High blood pressure $(\mathrm{COACH})$ study were well tolerated and were free of major side effects, the occurrence of pedal edema was less in those subjects medicated with the fixed-dose combination of $40 / 10 \mathrm{mg}$ of olmesartan/amlodipine (23.5\%) than in those subjects medicated with amlodipine alone (36.8\%). The reduction in peripheral edema in response to the addition of an ARB to a CCB is a product of the concurrent vasodilator effect of Ang II blockade inducing venular capillary dilatation, thus diminishing the pressure gradient across the peripheral microcirculation. ${ }^{38}$

A trial performed in Europe compared the effectiveness of a single-pill combination of olmesartan and amlodipine in a randomized, double-blind, parallel-group, multicenter trial in patients with moderate to severe hypertension (systolic blood 
pressure $[\mathrm{SBP}] \geq 160 \mathrm{mmHg}$ and diastolic blood pressure $[D B P] \geq 100 \mathrm{mmHg}$ ). ${ }^{39}$ Nonresponders to an open-label monotherapy phase with olmesartan ( 8 weeks at $20 \mathrm{mg} /$ day) were randomized to $20 \mathrm{mg}$ /day olmesartan plus placebo, the fixed-dose combination of $20 \mathrm{mg} /$ day olmesartan plus $5 \mathrm{mg}$ / day amlodipine, or $20 \mathrm{mg} /$ day olmesartan plus $10 \mathrm{mg} /$ day amlodipine for an additional 8 weeks. ${ }^{39}$ The primary end point evaluated the intention-to-treat population of all subjects with hypertension who received at least one dose of the double-blind study medication, had baseline measures of sitting DBP, and received at least one postrandomization measure of DBP $>140 / 90 \mathrm{mmHg}$. Potential confounders due to the use of the less rigorous statistical approach of last observation carried forward for missing data during the double-blind period were compensated by the inclusion of an observed case approach in which the last observation was not carried forward. Of the 1,519 screened subjects, 722 patients entered the open-label phase of the study with $20 \mathrm{mg} /$ day olmesartan. The 538 subjects who completed this phase of the study were randomized to the 8 -week double-blind period of one of the three interventions. The blood pressure of $<140 / 90 \mathrm{mmHg}$ after the 8 -week double-blind period was achieved in $28.5 \%, 44.5 \%$, and $45.8 \%$ of subjects randomized to olmesartan/placebo, $20 / 5 \mathrm{mg} /$ day olmesartan/amlodipine, and $20 / 10 \mathrm{mg} /$ day olmesartan/amlodipine, respectively. ${ }^{39}$ A post hoc analysis showed that the number of subjects reaching a DBP of $<90 \mathrm{mmHg}$ were greater in those using the fixed-dose combinations of olmesartan/amlodipine. ${ }^{39} \mathrm{In}$ addition, the study showed that the combination therapy was associated with an earlier reaching of their goal blood pressure when compared with the monotherapy phase. These data are in agreement with another study in which the combination of $10-40 \mathrm{mg} /$ day olmesartan with $5 \mathrm{mg}$ /day amlodipine for 8 weeks reduced the mean SBP and DBP by 16.8 and $9.6 \mathrm{mmHg}$, respectively. ${ }^{40}$

$\mathrm{SBP}$ is a predictor of increased cardiovascular risk. ${ }^{41}$ In a post hoc analysis of changes in sitting SBP in patients treated with $40 \mathrm{mg}$ of olmesartan plus $5-10 \mathrm{mg} /$ day amlodipine, ${ }^{40}$ the combination therapy was shown to be most effective in reducing SBP in the subjects with highest levels of SBP. ${ }^{42} \mathrm{As}$ reviewed elsewhere, ${ }^{43}$ this combination therapy is superior to the single-agent administration in other high-risk populations, such as African Americans, ${ }^{44}$ obese, and patients with diabetes. The predominant effect of improvement in insulin resistance and reduced oxidative stress seems to be related to blockade of Ang II receptors. ${ }^{45-49}$

Presence of chronic kidney disease aggravates the odds of cardiovascular events in patients with hypertension. ${ }^{50}$
The potential for renoprotective effects of combining a CCB with olmesartan in elderly patients (age 65-85 years) with chronic kidney disease was investigated in a crossover study using an open-label, randomized design with albuminuria (creatinine $>5 \mathrm{mg} / \mathrm{g}$ ). ${ }^{51}$ Following a 2-week run in observation period, the subjects were randomized to receive a starting dose of benidipine ( $4 \mathrm{mg} /$ day) or amlodipine combined with olmesartan $(5 / 10 \mathrm{mg} /$ day $)$. Three months later, the patients were switched from benidipine to amlodipine and followed-up for an additional 3 months. Benidipine is a dihydropyridine CCB that induces efferent arteriolar dilation through blockade of both L- and T-type calcium channels. ${ }^{52,53}$ Combination of olmesartan with either CCBs produced comparable decreases in arterial blood pressure, whereas the combination of benidipine and olmesartan achieved slightly greater statistically significant decreases in albumin excretion. ${ }^{51}$ The Randomized Olmesartan and Diabetes Prevention (ROADMAP) study determined the factors correlating with albumin excretion rates across the range of normoalbuminuric values in patients with type 2 diabetes using olmesartan medoxomil..$^{54,55}$

There is evidence that the administration of olmesartan is the key driver in achieving the target blood pressure in patients with stage II hypertension ${ }^{56}$ and reducing the effects of hypertension in vascular remodeling. ${ }^{31,32} \mathrm{~A}$ multicenter, 12-week study compared the efficacy, safety, and tolerability of a combination of olmesartan medoxomil/HCTZ with that of benazepril plus amlodipine besylate in patients with stage II hypertension. ${ }^{57}$ The data showed that the primary efficacy end point of change in mean seated SBP at week 12 was significantly greater with olmesartan medoxomil/HCTZ than with benazepril plus amlodipine besylate. ${ }^{57}$ These findings are in agreement with other studies documenting the efficacy of the combination of olmesartan/HCTZ in subjects with hypertension and in those with isolated systolic hypertension. ${ }^{44,58-60}$ As reviewed by Quan et al ${ }^{61}$ a multifactorial analysis of the published studies reported that the daily combination of $40 \mathrm{mg}$ olmesartan and $25 \mathrm{mg} \mathrm{HCTZ}$ produced greater blood pressure reductions than with the administration of $300 \mathrm{mg}$ irbesartan/25 mg HCTZ, $80 \mathrm{mg}$ telmisartan/12.5 mg HCTZ, and $160 \mathrm{mg}$ valsartan/25 mg HCTZ. ${ }^{62}$ The addition of HCTZ to patients receiving a fixeddose combination of olmesartan/amlodipine (40/5-10 mg/ day) increased the overall proportion of patients reaching the goal blood pressure. ${ }^{63}$ In an additional study that focused on reaching the blood pressure goals rather than the responder rates, with the combination of olmesartan medoxomil, amlodipine, and HCTZ, $90 \%$ of patients with 
stage 2 hypertension reached the blood pressure of $<140 / 90$ $\mathrm{mmHg}$ and $81 \%$ patients attained $<130 / 85 \mathrm{mmHg} .{ }^{64}$

Long-term outcome studies as to the benefit of the combination of olmesartan/amlodipine in the prevention of cardiovascular events are not yet available. To meet this objective, an on-going study will evaluate whether high-dose ARB monotherapy is superior to the combination therapy of ARB plus CCB in the prevention of cardiovascular morbidity and mortality in elderly Japanese high-risk patients with hypertension (OlmeSartan and Calcium Antagonists Randomized [OSCAR] Study). ${ }^{65}$

\section{Conclusions}

The importance of blood pressure control in the prevention of cardiovascular events is well established. Given the relative success in achieving appropriate blood pressure control in the general population, effective drug combinations as first-line therapy can meet the need to attain blood pressure levels $<140 / 90 \mathrm{mmHg}$ in uncomplicated hypertension and $\leq 130 / 80 \mathrm{mmHg}$ in subjects with diabetes or in those in whom hypertension is accompanied by chronic kidney disease. Although published guidelines advocate the combination of a thiazide diuretic with another antihypertensive agent as initial therapy, emerging evidence suggests that the association of a CCB with either an ACE inhibitor or an ARB may be a safer and more effective combination. ${ }^{66}$ Evidence for this approach is buttressed by the recent publication of the ACCOMPLISH study. ${ }^{5}$ In this study, the combination of the ACE inhibitor benazepril with the CCB amlodipine was more effective than the combination of benazepril with HCTZ in reducing the primary composite end point of cardiovascular events and death from cardiovascular causes over the 36-month mean follow-up period. ${ }^{5}$ The combination of olmesartan/ amlodipine in a fixed-dose combination has proven to be effective in controlling blood pressure in patients with stage 1 and stage 2 hypertension. ${ }^{4,37,38,44,56,66-73}$ Their additive antihypertensive effect is associated with complimentary actions that in part may be related to the buffering of the reactive increase in renin-angiotensin system activity triggered by the vasodilator action of amlodipine. ${ }^{74}$

Among the advantages of fixed combination therapy, several studies suggest that this approach overcomes issues related to side effects, patient and physician inertia, the proportion of subjects classified as resistant hypertension, and cost-effectiveness issues such as co-pays. ${ }^{43}$ In several observational studies, fixed-dose combinations were associated with higher rates of compliance, persistence, and adherence to treatment regimens. ${ }^{75-82}$ A meta-analysis of 15 published studies with a total of 32,331 patients concluded that fixed-dose combinations of antihypertensive agents were associated with increased compliance and no changes in the frequency of adverse events when compared with free drug components given separately. ${ }^{80}$

Interest in the effect of the circadian rhythm of blood pressure in terms of its association with the occurrence of cardiovascular events posits the question as to whether single-pill, fixed-dose combinations may provide greater benefit when administered at bedtime. Although the effectiveness of such a chronotherapeutic approach remains unexplored for single-pill, fixed-dose combinations, Minutolo et al ${ }^{83}$ reported that in nondipper subjects with chronic kidney disease changing the timing of antihypertensive therapy decreases nocturnal blood pressure and proteinuria. As reviewed by Stergiou et al $^{84}$ morning administration of single- or fixeddose combinations of drugs have been used in assessing the efficacy of antihypertensive therapy. In bedtime dosing of treatment as used in the Controlled Onset Verapamil Investigation of Cardiovascular Endpoints (CONVINCE) trial, chronotherapeutical dosing of verapamil failed to blunt the early morning surge in blood pressure. ${ }^{85}$ In contrast, the bedtime dosing of ramipril in the Heart Outcomes Prevention Evaluation (HOPE) trial has been suggested to partially account for the vascular benefits found in this study. ${ }^{86}$ The efficacy of olmesartan medoxomil in controlling blood pressure over a 24-hour period showed that the ARB was more effective than losartan and valsartan in maintaining lower levels of blood pressure for mean daytime and nighttime ambulatory blood pressure. ${ }^{87}$ Although further work will be necessary to evaluate these possibilities, it is undeniable that the use of a single-pill, fixed-dose combination at bedtime should be explored in well-controlled clinical trials.

\section{Acknowledgments}

In addition to the support provided by NHLBI grant PO1 HL051952, the authors gratefully acknowledge the grant support provided by Unifi, Inc., Greensboro, NC, and Farley-Hudson Foundation, Jacksonville, NC.

\section{Disclosure}

Carlos M Ferrario receives compensation for speaking and consulting with Daiichi Sankyo Corporation, Novartis, Inc., Forest Research, Bristol-Myers Squibb, Takeda, and Merck Inc.

\section{References}

1. Mancia G, Laurent S, Agabiti-Rosei E, et al. Reappraisal of European guidelines on hypertension management: a European Society of Hypertension Task Force document. Blood Press. 2009;18: 308-347. 
2. Mancia G, Zanchetti A. European Society of Hypertension-European Society of Cardiology. Choice of antihypertensive drugs in the European Society of Hypertension-European Society of Cardiology guidelines: specific indications rather than ranking for general usage. J Hypertens. 2008;26:164-168.

3. Zanchetti A, Mancia G, Black HR, et al. Facts and fallacies of blood pressure control in recent trials: implications in the management of patients with hypertension. J Hypertens. 2009;27:673-679.

4. Izzo JL Jr, Purkayastha D, Hall D, Hilkert RJ. Comparative efficacy and safety of amlodipine/benazepril combination therapy and amlodipine monotherapy in severe hypertension. J Hum Hypertens. 2010;24: 403-409.

5. Jamerson K, Weber MA, Bakris GL, et al. Benazepril plus amlodipine or hydrochlorothiazide for hypertension in high-risk patients. $N$ Engl J Med. 2008;359:2417-2428.

6. Brunner HR. The new oral angiotensin II antagonist olmesartan medoxomil: a concise overview. J Hum Hypertens. 2002;16 Suppl 2:S13-S16.

7. Brunner HR, Laeis P. Clinical efficacy of olmesartan medoxomil. J Hypertens Suppl. 2003;21:S43-S46.

8. Ferrario C. Effect of angiotensin receptor blockade on endothelial function: focus on olmesartan medoxomil. Vasc Health Risk Manag. 2009;5:301-314.

9. Schindler C, Ferrario CM. Olmesartan for the treatment of arterial hypertension. Future Cardiol. 2008;4:357-372.

10. Koike H, Sada T, Mizuno M. In vitro and in vivo pharmacology of olmesartan medoxomil, an angiotensin II type AT1 receptor antagonist. J Hypertens Suppl. 2001;19:S3-S14.

11. Koike H. New pharmacologic aspects of CS-866, the newest angiotensin II receptor antagonist. Am J Cardiol. 2001;87:33C-36C.

12. Laeis P, Puchler K, Kirch W. The pharmacokinetic and metabolic profile of olmesartan medoxomil limits the risk of clinically relevant drug interaction. J Hypertens Suppl. 2001;19:S21-S32.

13. Mizuno M, Sada T, Ikeda M, et al. Pharmacology of CS-866, a novel nonpeptide angiotensin II receptor antagonist. Eur J Pharmacol. 1995;285:181-188.

14. Yoshida K, Kohzuki M. Clinical and experimental aspects of olmesartan medoxomil, a new angiotensin II receptor antagonist. Cardiovasc Drug Rev. 2004;22:285-308.

15. Murdoch D, Heel RC. Amlodipine. A review of its pharmacodynamic and pharmacokinetic properties, and therapeutic use in cardiovascular disease. Drugs. 1991;41:478-505.

16. Rohatagi S, Lee J, Shenouda M, et al. Pharmacokinetics of amlodipine and olmesartan after administration of amlodipine besylate and olmesartan medoxomil in separate dosage forms and as a fixed-dose combination. J Clin Pharmacol. 2008;48:1309-1322.

17. Fliser D, Buchholz K, Haller H. Antiinflammatory effects of angiotensin II subtype 1 receptor blockade in hypertensive patients with microinflammation. Circulation. 2004;110:1103-1107.

18. Lorenzen JM, Neunhoffer H, David S, Kielstein JT, Haller H, Fliser D. Angiotensin II receptor blocker and statins lower elevated levels of osteopontin in essential hypertension - results from the EUTOPIA trial. Atherosclerosis. 2010;209:184-188.

19. Miyazaki M, Takai S. Anti-atherosclerotic efficacy of olmesartan. J Hum Hypertens. 2002;16 Suppl 2:S7-S12.

20. Ichikawa S, Takayama Y. Long-term effects of olmesartan, an Ang II receptor antagonist, on blood pressure and the renin-angiotensinaldosterone system in hypertensive patients. Hypertens Res. 2001;24: 641-646.

21. Schindler C, Brosnihan KB, Ferrario CM, et al. Comparison of inhibitory effects of irbesartan and atorvastatin treatment on the renin angiotensin system (RAS) in veins: a randomized double-blind crossover trial in healthy subjects. J Clin Pharmacol. 2007;47:112-120.

22. Crackower MA, Sarao R, Oudit GY, et al. Angiotensin-converting enzyme 2 is an essential regulator of heart function. Nature. 2002;417: 822-828.

23. Ferrario CM, Jessup J, Chappell MC, et al. Effect of angiotensin-converting enzyme inhibition and angiotensin II receptor blockers on cardiac angiotensin-converting enzyme 2. Circulation. 2005;111: 2605-2610.
24. Ferrario CM, Trask AJ, Jessup JA. Advances in biochemical and functional roles of angiotensin-converting enzyme 2 and angiotensin-(1-7) in regulation of cardiovascular function. Am J Physiol Heart Circ Physiol. 2005;289:H2281-H2290.

25. Ferrario CM. New physiological concepts of the renin-angiotensin system from the investigation of precursors and products of angiotensin I metabolism. Hypertension. 2010;55:445-452.

26. Gallagher PE, Ferrario CM, Tallant EA. Regulation of ACE2 in cardiac myocytes and fibroblasts. Am J Physiol Heart Circ Physiol. 2008;295:H2373-H2379.

27. Tallant EA, Ferrario CM, Gallagher PE. Angiotensin-(1-7) inhibits growth of cardiac myocytes through activation of the mas receptor. Am J Physiol Heart Circ Physiol. 2005;289:H1560-H1566.

28. Agata J, Ura N, Yoshida H, et al. Olmesartan is an angiotensin II receptor blocker with an inhibitory effect on angiotensin-converting enzyme. Hypertens Res. 2006;29:865-874.

29. Smith RD, Yokoyama H, Averill DB, et al. The protective effects of angiotensin II blockade with olmesartan medoxomil on resistance vessel remodeling (The VIOS study): rationale and baseline characteristics. Am J Cardiovasc Drugs. 2006;6:335-342.

30. Stumpe KO. Olmesartan compared with other angiotensin II receptor antagonists: head-to-head trials. Clin Ther. 2004;26 Suppl A: A33-A37.

31. Miyashita Y, Saiki A, Endo K, et al. Effects of olmesartan, an angiotensin II receptor blocker, and amlodipine, a calcium channel blocker, on Cardio-Ankle Vascular Index (CAVI) in type 2 diabetic patients with hypertension. $J$ Atheroscler Thromb. 2009; 16:621-626.

32. Smith RD, Yokoyama H, Averill DB, Schiffrin EL, Ferrario CM. Reversal of vascular hypertrophy in hypertensive patients through blockade of angiotensin II receptors. J Am Soc Hypertens. 2008;2:165-172.

33. Schiffrin EL, Deng LY, Larochelle P. Morphology of resistance arteries and comparison of effects of vasoconstrictors in mild essential hypertensive patients. Clin Invest Med. 1993;16:177-186.

34. Schiffrin EL, Deng LY, Larochelle P. [Prospective study of the effects of an angiotensin converting enzyme inhibitor and a beta blockader on the structure and function of resistant arteries in mild essential hypertension]. Arch Mal Coeur Vaiss. 1994;87:979-981.

35. Asmar R, Rudnichi A, Blacher J, London GM, Safar ME. Pulse pressure and aortic pulse wave are markers of cardiovascular risk in hypertensive populations. Am J Hypertens. 2001;14:91-97.

36. Rosenson RS. Treatment of hypertension in metabolic syndrome subjects with amlodipine and olmesartan-effects on oxidized nonesterified free fatty acids and cytokine production. Cardiovasc Drugs Ther. 2009;23:289-294.

37. Chrysant SG, Melino M, Karki S, Lee J, Heyrman R. The combination of olmesartan medoxomil and amlodipine besylate in controlling high blood pressure: $\mathrm{COACH}$, a randomized, double-blind, placebocontrolled, 8-week factorial efficacy and safety study. Clin Ther. 2008;30:587-604.

38. Chrysant SG. Amlodipine besylate/olmesartan medoximil fixed combination for the treatment of hypertension. Expert Rev Cardiovasc Ther. 2009;7:887-895.

39. Barrios V, Brommer P, Haag U, Calderon A, Escobar C. Olmesartan medoxomil plus amlodipine increases efficacy in patients with moderate-to-severe hypertension after monotherapy: a randomized, double-blind, parallel-group, multicentre study. Clin Drug Investig. 2009;29:427-439.

40. Volpe M, Brommer P, Haag U, Miele C. Efficacy and tolerability of olmesartan medoxomil combined with amlodipine in patients with moderate to severe hypertension after amlodipine monotherapy: a randomized, double-blind, parallel-group, multicentre study. Clin Drug Investig. 2009;29:11-25.

41. Lewington S, Clarke R, Qizilbash N, Peto R, Collins R, Prospective SC. Age-specific relevance of usual blood pressure to vascular mortality: a meta-analysis of individual data for one million adults in 61 prospective studies. Lancet. 2002;360:1903-1913. 
42. Mourad JJ, Le JS. Effective systolic blood pressure reduction with olmesartan medoxomil/amlodipine combination therapy: post hoc analysis of data from a randomized, double-blind, parallel-group, multicentre study. Clin Drug Investig. 2009;29:419-425.

43. Basile J, Neutel J. Overcoming clinical inertia to achieve blood pressure goals: the role of fixed-dose combination therapy. Ther Adv Cardiovasc Dis. 2010;4:119-127.

44. Oparil S, Chrysant SG, Kereiakes D, et al. Results of an olmesartan medoxomil-based treatment regimen in hypertensive patients. $J$ Clin Hypertens (Greenwich). 2008;10:911-921.

45. de Vinuesa SG, Goicoechea M, Kanter J, et al. Insulin resistance, inflammatory biomarkers, and adipokines in patients with chronic kidney disease: effects of angiotensin II blockade. J Am Soc Nephrol. 2006;17:S206-S212.

46. Fogari R, Derosa G, Zoppi A, et al. Effects of manidipine/delapril versus olmesartan/hydrochlorothiazide combination therapy in elderly hypertensive patients with type 2 diabetes mellitus. Hypertens Res. 2008;31:43-50.

47. Fogari R, Derosa G, Zoppi A, et al. Effect of delapril/manidipine vs olmesartan/hydrochlorothiazide combination on insulin sensitivity and fibrinogen in obese hypertensive patients. Intern Med. 2008;47:361-366.

48. Kurita $\mathrm{S}$, Takamura $\mathrm{T}$, Ota $\mathrm{T}$, et al. Olmesartan ameliorates a dietary rat model of non-alcoholic steatohepatitis through its pleiotropic effects. Eur J Pharmacol. 2008;588:316-324.

49. Zaman AK, Fujii S, Goto D, et al. Salutary effects of attenuation of angiotensin II on coronary perivascular fibrosis associated with insulin resistance and obesity. J Mol Cell Cardiol. 2004;37:525-535.

50. Klag MJ, Whelton PK, Randall BL, et al. Blood pressure and end-stage renal disease in men. $N$ Engl J Med. 1996;334:13-18.

51. Miyagawa K, DohiY, Nakazawa A, et al. Renoprotective effect of calcium channel blockers in combination with an Angiotensin receptor blocker in elderly patients with hypertension. A randomized crossover trial between benidipine and amlodipine. Clin Exp Hypertens. 2010; 32:1-7.

52. Furukawa T, Nukada T, Miura R, et al. Differential blocking action of dihydropyridine $\mathrm{Ca} 2+$ antagonists on a T-type $\mathrm{Ca} 2+\operatorname{channel}(\mathrm{alpha} 1 \mathrm{G})$ expressed in Xenopus oocytes. J Cardiovasc Pharmacol. 2005; 45:241-246.

53. Morikawa T, Okumura M, Konishi Y, Okada N, Imanishi M. Effects of benidipine on glomerular hemodynamics and proteinuria in patients with nondiabetic nephropathy. Hypertens Res. 2002;25:571-576.

54. Haller H, Viberti GC, Mimran A, et al. Preventing microalbuminuria in patients with diabetes: rationale and design of the Randomised Olmesartan and Diabetes Microalbuminuria Prevention (ROADMAP) study. J Hypertens. 2006;24:403-408.

55. Ritz E, Viberti GC, Ruilope LM, et al. Determinants of urinary albumin excretion within the normal range in patients with type 2 diabetes: the Randomised Olmesartan and Diabetes Microalbuminuria Prevention (ROADMAP) study. Diabetologia. 2010;53:49-57.

56. Chrysant SG, Marbury TC, Silfani TN. Use of 24-h ambulatory blood pressure monitoring to assess blood pressure control: a comparison of olmesartan medoxomil and amlodipine besylate. Blood Press Monit. 2006; 11:135-141.

57. Kereiakes DJ, Neutel JM, Punzi HA, Xu J, Lipka LJ, Dubiel R. Efficacy and safety of olmesartan medoxomil and hydrochlorothiazide compared with benazepril and amlodipine besylate. Am J Cardiovasc Drugs. 2007;7:361-372.

58. Chrysant SG, Chrysant GS. Antihypertensive efficacy of olmesartan medoxomil alone and in combination with hydrochlorothiazide. Expert Opin Pharmacother. 2004;5:657-667.

59. Chrysant SG, Weber MA, Wang AC, Hinman DJ. Evaluation of antihypertensive therapy with the combination of olmesartan medoxomil and hydrochlorothiazide. Am J Hypertens. 2004; 17:252-259.
60. Izzo JL Jr, Neutel JM, Silfani T, Dubiel R, Walker F. Efficacy and safety of treating stage 2 systolic hypertension with olmesartan and olmesar$\tan / \mathrm{HCTZ}$ : results of an open-label titration study. J Clin Hypertens (Greenwich). 2007;9:36-44.

61. Quan A, Chavanu K, Merkel J. A review of the efficacy of fixed-dose combinations olmesartan medoxomil/hydrochlorothiazide and amlodipine besylate/benazepril in factorial design studies. Am J Cardiovasc Drugs. 2006;6:103-113.

62. Ram CV. Antihypertensive efficacy of angiotensin receptor blockers in combination with hydrochlorothiazide: a review of the factorial-design studies. J Clin Hypertens (Greenwich). 2004;6:569-577.

63. Volpe M, Miele C, Haag U. Efficacy and safety of a stepped-care regimen using olmesartan medoxomil, amlodipine and hydrochlorothiazide in patients with moderate-to-severe hypertension: an open-label, long-term study. Clin Drug Investig. 2009;29:381-391.

64. Neutel JM, Smith DH, Silfani TN, Lee Y, Weber MA. Effects of a structured treatment algorithm on blood pressure goal rates in both stage 1 and stage 2 hypertension. J Hum Hypertens. 2006;20: 255-262.

65. Ogawa H, Kim-Mitsuyama S, Jinnouchi T, Matsui K, Arakawa K. Rationale, design and patient baseline characteristics of OlmeSartan and calcium antagonists randomized (OSCAR) study: a study comparing the incidence of cardiovascular events between high-dose angiotensin II receptor blocker (ARB) monotherapy and combination therapy of ARB with calcium channel blocker in Japanese elderly high-risk hypertensive patients (Clinical Trials gov no. NCT00134160). Hypertens Res. 2009; $32: 575-580$

66. Oparil S, Lee J, Karki S, Melino M. Subgroup analyses of an efficacy and safety study of concomitant administration of amlodipine besylate and olmesartan medoxomil: evaluation by baseline hypertension stage and prior antihypertensive medication use. J Cardiovasc Pharmacol. 2009;54:427-436.

67. Chrysant SG. Amlodipine/ARB fixed-dose combinations for the treatment of hypertension: focus on amlodipine/olmesartan combination. Drugs Today (Barc). 2008;44:443-453.

68. Chrysant SG, Oparil S, Melino M, Karki S, Lee J, Heyrman R. Efficacy and safety of long-term treatment with the combination of amlodipine besylate and olmesartan medoxomil in patients with hypertension. J Clin Hypertens (Greenwich). 2009;11:475-482.

69. Neutel JM, Smith DH, Weber MA, Wang AC, Masonson HN. Use of an olmesartan medoxomil-based treatment algorithm for hypertension control. J Clin Hypertens (Greenwich). 2004;6:168-174.

70. Neutel JM. Prescribing patterns in hypertension: the emerging role of fixed-dose combinations for attaining BP goals in hypertensive patients. Curr Med Res Opin. 2008;24:2389-2401.

71. Oparil S, Williams D, Chrysant SG, Marbury TC, Neutel J. Comparative efficacy of olmesartan, losartan, valsartan, and irbesartan in the control of essential hypertension. J Clin Hypertens (Greenwich). 2001;3: 283-291, 318

72. Oparil S, Weber M. Angiotensin receptor blocker and dihydropyridine calcium channel blocker combinations: an emerging strategy in hypertension therapy. Postgrad Med. 2009;121:25-39.

73. Oparil S, Pimenta E. Efficacy of an olmesartan medoxomil-based treatment algorithm in patients stratified by age, race, or sex. J Clin Hypertens (Greenwich). 2010;12:3-13.

74. Cappuccio FP, Markandu ND, Sagnella GA, et al. Effects of amlodipine on urinary sodium excretion, renin-angiotensin-aldosterone system, atrial natriuretic peptide and blood pressure in essential hypertension. J Hum Hypertens. 1991;5:115-119.

75. Bramlage P. Fixed combination of irbesartan and hydrochlorothiazide in the management of hypertension. Vasc Health Risk Manag. 2009;5: 213-224.

76. Bramlage P, Hasford J. Blood pressure reduction, persistence and costs in the evaluation of antihypertensive drug treatment - a review. Cardiovasc Diabetol. 2009;8:18. 
77. Bramlage P. Fixed-dose combinations of renin-angiotensin blocking agents with calcium channel blockers or hydrochlorothiazide in the treatment of hypertension. Expert Opin Pharmacother. 2009;10: 1755-1767.

78. Calhoun DA. Use of single-pill combination therapy in the evolving paradigm of hypertension management. Expert Opin Pharmacother. 2009;10:1869-1874

79. Calhoun DA, Crikelair NA, Yen J, Glazer RD. Amlodipine/valsartan/ hydrochlorothiazide triple combination therapy in moderate/severe hypertension: secondary analyses evaluating efficacy and safety. Adv Ther. 2009;26:1012-1023.

80. Gupta AK, Arshad S, Poulter NR. Compliance, safety, and effectiveness of fixed-dose combinations of antihypertensive agents: a meta-analysis. Hypertension. 2010;55:399-407.

81. Sica DA. Rationale for fixed-dose combinations in the treatment of hypertension: the cycle repeats. Drugs. 2002;62:443-462.

82. Zarowitz BJ. Fixed-dose combinations for improving medication adherence in assisted living environments. Geriatr Nurs. 2007;28 $341-345$
83. Minutolo R, Gabbai FB, Borrelli S, et al. Changing the timing of antihypertensive therapy to reduce nocturnal blood pressure in CKD: an 8-week uncontrolled trial. Am J Kidney Dis. 2007;50:908-917.

84. Stergiou GS, Nasothimiou EG. Does dosing antihypertensive drugs at night alter renal or cardiovascular outcome: do we have the evidence? Curr Opin Nephrol Hypertens. 2008;17:464-469.

85. Black HR, Elliott WJ, Grandits G, et al. Principal results of the Controlled Onset Verapamil Investigation of Cardiovascular End Points (CONVINCE) trial. JAMA. 2003;289:2073-2082.

86. Yusuf S, Sleight P, Pogue J, Bosch J, Davies R, Dagenais G. The Heart Outcomes Prevention Evaluation Study Investigators. Effects of an angiotensin-converting-enzyme inhibitor, ramipril, on cardiovascular events in high-risk patients. $N$ Engl J Med. 2000;342:145-153.

87. Smith DH, Dubiel R, Jones M. Use of 24-hour ambulatory blood pressure monitoring to assess antihypertensive efficacy: a comparison of olmesartan medoxomil, losartan potassium, valsartan, and irbesartan Am J Cardiovasc Drugs. 2005;5:41-50.
Vascular Health and Risk Management

\section{Publish your work in this journal}

Vascular Health and Risk Management is an international, peerreviewed journal of therapeutics and risk management, focusing on concise rapid reporting of clinical studies on the processes involved in the maintenance of vascular health; the monitoring, prevention and treatment of vascular disease and its sequelae; and the involvement of

\section{Dovepress}

metabolic disorders, particularly diabetes. This journal is indexed on PubMed Central and MedLine. The manuscript management system is completely online and includes a very quick and fair peer-review system, which is all easy to use. Visit http://www.dovepress.com/ testimonials.php to read real quotes from published authors.

Submit your manuscript here: http://www.dovepress.com/vascular-health-and-risk-management-journal 